\title{
Acute Normalization of Thyroxine Induced Hallucinations and Delusions
}

\author{
Yuko Furuhashi $^{1}$, Masaya Ishikawa ${ }^{2}$ \\ ${ }^{1}$ Medical Center, Shizuoka University, Shizuoka, Japan; ${ }^{2}$ Saginuma Park Clinic, Kawasaki, Japan. \\ Email: oyfuruh@ipc.shizuoka.ac.jp
}

Received June $15^{\text {th }}, 2012$; revised July $16^{\text {th }}, 2012$; accepted July $25^{\text {th }}, 2012$

\begin{abstract}
The association between disorders of thyroid function and psychiatric symptoms is well established. Generally, hypothyroidism is recognized as being able to induce psychotic symptoms. However, psychotic symptoms without affective and cognitive disturbances are rare in hyperthyroidism. We presented a patient with Graves' disease who suffered from delusions and hallucinations without affective and cognitive disturbances following abrupt normalization of thyroid function. Furthermore, the patient was clinically and biochemically euthyroid when the psychotic symptoms developed. There was resolution of psychotic symptoms in this case. It is suggested that the abrupt change of thyroxine may cause susceptible individuals to become transient psychotic state.
\end{abstract}

Keywords: Graves’ Disease; Hallucination, Delusion

\section{Introduction}

Graves' disease is a form of hyperthyroidism associated with diffuse goiter, ophthalmopathy, and dermopahty. This is believed to be an autoimmune disease that is multifactorial in organ [1]. Patients with Graves' disease may experience emotional lability, tremors, sinus tachycardia, restlessness, excessive sweating, and impaired ability to concentrate [1-3].

While the association between disorders of thyroid function and affective symptoms is well established [1-6], it is rare that psychotic symptoms without affective and cognitive disturbances in patients with Graves' disease $[7,8]$. The following is a case of new-onset psychosis in a woman who underwent isotope irradiation therapy of Graves’ disease.

\section{Case}

Ms. A is a 36-year-old woman, who had married and had three children, complained of palpitation, excessive sweating, and finger tremors. Laboratory tests at that time showed serum level of free thyroxine (free $\mathrm{T}_{4}$ ) was $6.4 \mathrm{ng} / \mathrm{dL}$ (normal range $0.9-2.0 \mathrm{ng} / \mathrm{dL}$ ) and serum thyroid-stimulating hormone (TSH) level was under the detection level $(<0.05 \mu \mathrm{U} / \mathrm{mL}$, normal range $0.3-4.1$ $\mu \mathrm{U} / \mathrm{mL}$ ). Serum antibodies to thyroglobulin, microsomes, and thyrotropin were positive. She was diagnosed as Graves' disease. Thiamazole (MMI) $30 \mathrm{mg}$ a day was administrated with good compliance, but the white blood cell counts were reduced to $980 / \mathrm{mm}^{3}$. The MMI was replaced with Propylthiouracil (PTU). She exhibited poor control (free $\mathrm{T}_{4} 6.0 \mathrm{ng} / \mathrm{dL}$ ) even when PTU was administrated $1200 \mathrm{mg}$ a day. Her symptoms such as irritability and general fatigue deteriorated in parallel with an increase of serum free $T_{4}$ level $(9.8 \mathrm{ng} / \mathrm{dL})$. She was sent to our hospital to be treated by isotope irradiation therapy.

On admission, the patient was a slightly thin woman with finger tremors but no exophthalmos. She was alert. She had a family history of hyperthyroidism in her father. She had no prior psychiatric history and did not receive a psychiatric treatment. There was no history of recent or past alcohol or illegal drug use. At that time of admission, she had routine laboratory tests and imaging studies. Although her free $\mathrm{T}_{4}$ level was $10.4 \mathrm{ng} / \mathrm{dL}$ and TSH level was under the detection level, other data including electrolytes and brain magnetic resonance were all normal. A week after her admission, isotope irradiation therapy on the thyroid was tried for in place of medication. At that time the irradiation therapy was ended, her serum free $\mathrm{T}_{4}$ level was $13.4 \mathrm{ng} / \mathrm{dL}$. She complained severe general fatigue and palpitation. Four weeks after irradiation therapy, her serum free $T_{4}$ level was $2.0 \mathrm{ng} / \mathrm{dL}$. Along with the improvement of thyroid hormone level, physical symptoms such as palpitation, sweating, and hand tremors fully improved. Then, she suddenly suffered an abrupt ongoing auditory hallucinations of multiple and indistinct voices. She reported that someone had been talking critically of her and sometimes commanded her 
to kill herself. In addition, she insisted that her conversations were recorded all the time and she was watched by surveillance cameras. In spite of hallucinations and delusions, she did not present any predominant affective symptoms. She was fully orientated for time and place, and her cognitive functions were not disturbed. She was treated with haloperidol (HPD) 9 mg a day. Immediately her psychotic symptoms responded to HPD. She was discharged seven weeks after the irradiation therapy was ended. At her discharge, her serum free $\mathrm{T}_{4}$ level was 1.0 ng/dl. Consecutive examinations revealed that her serum TSH level had been under the detection level until she was discharged. Two weeks after her discharge, HPD was discontinued because her psychotic symptoms were improved. Six months after her initial presentation in our hospital, she has remained in a euthyroid state and symptom free with no return of psychotic symptoms.

\section{Discussion}

Patients with Graves' disease may experience emotional lability, tremors, sinus tachycardia, restlessness, excessive sweating, and impaired ability to concentrate. A minority of patients, usually the elderly, are apathetic, depressed, and withdrawn [1].

Recent prospective studies suggest that there is an association between abnormalities of thyroid function and affective illness [2-4]. A lack of thyroid hormones can lower the threshold for depressive state, on the other hand, an excess of thyroid hormones can contribute to manic state. These findings suggest a possible central effect, either due to alterations of brain thyroid hormone homeostasis or, perhaps, to autoimmunity involvement in the brain. On the contrary, various studies have reported that psychiatric symptoms do not correlate with the degree of elevation of thyroid hormone levels [1,5-6]. For example, Trzepacz et al. [1] reported that there were no relationships between the clinical assessment of disease severity and serum levels of thyroid hormone. This discrepancy may arise if serum levels do not reflect intracellular thyroid hormone concentrations, or if there are cellular variations in nuclear thyroid hormone receptor sensitivity.

Thus, the association between disorders of thyroid function and psychiatric symptoms is well established [1-6], it is rare that psychotic symptoms in patients with Graves' disease [7-15].

A Medline search was performed using the search terms, "Graves' disease and psychosis”, "Graves' disease and delusions”, "Graves' disease and hallucinations”, "Graves' disease and paranoia”. Our search revealed only eight case reports of psychotic symptoms linked to Graves' disease [8-15]. Of these, three cases [8-10] have a certain similarity to our case. Katsigiannopoulos et al. [8] reported the patient who developed a psychotic dis- order without affective and cognitive disturbances in thyrotoxic state. Bewher et al. [9] and Irwin et al. [10] reported the case of a patient with Graves' disease who suffered from psychotic symptoms with manic features following abrupt normalization of thyroid functions.

Our case is especially interesting as the patient with Graves' disease who suffered from delusions and hallucinations without affective and cognitive disturbances following abrupt normalization of thyroid function. It seems possible that a rapid reduction in high ambient thyroid hormone tissue levels could lead to alteration, or recovery, of cellular function at different rates in different regions of the brain. This process may have triggered the transient psychotic features seen in our case. In those reports $[9,10]$ and our case, it is suggested that the rapid change in thyroid hormone levels might induce psychotic symptoms in susceptible individuals. Thyroid hormones and their receptors spread widely in the human brain, and thyroid hormones act on neural transmission as direct neurotransmitters by themselves [2]. These data suggest that a small change of serum thyroid hormone may induce a change in mental condition, however, the reason for this discrepancy and the pathogenesis of psychosis in Graves' disease are still elusive. The molecular mechanisms and functional pathways underlying the modulatory effects of thyroid hormones on mental status remain to be fully elucidated. Further studies and the accumulation of data of thyroid hormones on mental status are required.

\section{Conclusion}

General practitioners should bear in mind the possibility of psychotic symptoms following aggressive treatment of severe Graves’ disease.

\section{REFERENCES}

[1] P. T. Trzepacz, I. Klein, M. Roberts, J. Greeahouse and G. S. Lerey, "Greaves' Disease: An Analysis of Thyroid Hormone Levels and Hyperthyroid Sign and Symptoms," American Journal of Medicine, Vol. 87, No. 5, 1989, pp. 558-561. doi:10.1016/S0002-9343(89)80614-X

[2] R. A. Stern, B. Robinson, A. R. Thorner, J. E. Arruda, M. L. Prohaska and A. J. Prange Jr., "A Survey Study of Neuropsychiatric Complaints in Patients with Graves' Disease," Journal of Neuropsychiatry, Vol. 8, No. 2, 1996, pp. 181-185.

[3] P. C. Whybrow and A. J. Prange Jr., "A Hypothesis of Thyroid-Catecholamine-Receptor Interaction: Its Relevance to Affective Illness,” Archives of General Psychiatry, Vol. 38, 1981, pp. 106-113. doi:10.1001/archpsyc.1981.01780260108012

[4] K. D. Denicoff, R. T. Joffe, M. C. Lakshmanan, J. Robbinset and D. R. Robinowal, "Neuropsychiatric Manifestations of Altered Thyroid State," American Journal of 
Psychiatry, Vol. 147, No. 1, 1990, pp. 94-99.

[5] A. J. White and B. Barraclough, "Thyroid Disease and Mental Illness: A Study of Thyroid Disease in Psychiatric Admissions," Journal of Psychosomatic Research, Vol. 32, No. 1, 1988, pp. 99-106. doi:10.1016/0022-3999(88)90093-1

[6] R. P. Roca, M. R. Blackman, M. B. Ackerley, S. M. Harman and R. I. Gregerman, "Thyroid Hormone Elevations during Acute Psychiatric Illness: Relationship to Severity and Distinction from Hyperthyroidism," Endocrine Research, Vol. 16, No. 4, 1990, pp. 415-447. doi:10.1080/07435809009107116

[7] S. Benvenga, D. Lapa and F. Trimarchi, "Don't Forget the Thyroid in the Etiology of Psychoses," American Journal of Medicine, Vol. 115, 2003, pp. 159-160. doi:10.1016/S0002-9343(03)00298-5

[8] K. Katsigiannopoulos, E. Georgiadou, P. Pazarlis, A, Karastergiou, G. Papazisis, V. Bozikas and G. Garyfallos, "Psychotic Disorder as a Manifestation of Graves' Disease,” Psychosomatics, Vol. 51, No. 5, 2010, pp. 449450. doi:10.1016/S0033-3182(10)70732-5

[9] P. D. Bewher, A. Q. Gardiner, A. J. Hedley and H. C. S. Maclean, "Psychosis after Acute Alteration of Thyroid Status," Psychological Medicine, No. 1, 1971, pp. 260262. doi:10.1017/S0033291700041891

[10] R. Irwin, P. M. Ellis and J. Delahunt, "Psychosis Following Acute Alteration of Thyroid Status,” Australian and
New Zealand Journal of Psychiatry, Vol. 32, No. 5, 1997, pp. 67-71.

[11] T. Snabboon, A. Khemkha, C. Chaiyaumporn, D. Lalitanantpong and V. Sridama, "Psychosis as the First Presentation of Hyperthyroidism," Internal and Emergency Medicine, Vol. 4, No. 4, 2009, pp. 359-360. doi:10.1007/s11739-009-0259-y

[12] G. Manian, E. A. Nica and B. E. Ionescu, "Hyperthyroidism Cause of Depression and Psychosis: A Case Report," Journal of Medicine and Life, Vol. 2, No. 2, 2009, pp. 440-442.

[13] A. A. Rizvi, "Thyrotoxic Psychosis Associated with Subacute Thyroiditis,” South Medical Journal, Vol. 100, No. 8, 2007, pp. 837-840. doi:10.1097/SMJ.0b013e318063ed4e

[14] B. E. W. Brownlie, A. M. Rae, J. W. B. Walshe and J. E. Wells, "Psychoses Associated with Thyrotoxicosis-'Thyrotoxic Psychosis.’ A Report of 18 Cases, with Statistical Analysis of Incidence,” European Journal of Endocinology, Vol. 142, 2000, pp. 438-444. doi:10.1530/eje.0.1420438

[15] N. Kobayashi, J. Tajiri and M. Takano, "Transient Psychosis Due to Painless Thyroiditis in a Patient with Anxiety Disorder: A Case Report,” Journal of Medical Case Reports, Vol. 5, 2011, p. 534. doi:10.1186/1752-1947-5-534 